\title{
The non-cell autonomy of human gametes
}

\author{
David F. Albertini ${ }^{1}$ \\ Published online: 2 March 2018 \\ (C) Springer Science+Business Media, LLC, part of Springer Nature 2018
}

Despite our efforts as taskmasters, we continue to search for that perfect pair of gametes to recombine on the hopeful way to embryo transfer; the outcome inadequacies of such searches remain poor in clinical terms. As ARTs evolved, the notion that gamete developmental proficiency would be evident in intrinsic morphological appearances or other extragametic (read niche) biomarkers of said gamete's potential as embryo generators has settled deeply into the mindset of contemporary ART practitioners.

While it is indisputable that it takes two to tango for fertilization to launch advanced states of embryo development, the essence of gamete quality is beginning to look a bit like the case of throwing the baby out with the bath water. How so?

It is coming down to a matter of the niche - that series of environmental influences gametes are subjected to during their tortuous and saltatory transitions through the gonads and reproductive tracts prior to, during, and following fertilization. For the oocyte, the spatial niche is the ovarian follicle that over time will confer, cooperate, and coddle its cargo through the mucky media of ovulation consumed at the ovary - tubal interface. Matters of maturity and deliverance for the male gamete are, in striking contrast, altogether a different beast.

The road to fertilization for the male gamete is long and winding and not without sequential visits to a range of niches, beginning in the depths of the seminiferous epithelium, and for a select few, ending in the perivitelline space. As independentminded as some might suggest, at each of these waystations spermatozoa get involved with vicinal and distinct somatic cells in an open market-style trading of commodities, the substance of which is gaining currency. On the trading table lie membrane modifying lipids, ionic baths, and sperm cell surface altering proteins that together adjust and establish properties that will contribute to the male gamete's overall reproductive potential. Exchanges of this kind constitute sum and substance

David F. Albertini

eicjarg@gmail.com

1 The Center for Human Reproduction, New York, NY, USA for that portion of the journey residing in the epididymis. And no doubt these small but substantive alterations are part of the puzzle, but exactly what dimension of the sperm's makeover is directly tied to fertilizing potential physiologically remains clouded, especially in these days of post-ICSI ARTs.

However, clues are emerging from studies on animal models that do not fall into the world of Rodentia. Importantly, the mechanisms mediating the "reach-out-andtouch-someone" for gametes in need of niche support are finding common ground for both sexes in the form of exosomes. Center stage on the male side is fast becoming the epididymosome, the so-named vesicles released by the epididymal epithelium that had been implicated in earlier versions of the sperm makeover alluded to above [1].

Our featured article combines both elements of choosing an appropriate animal model (does anybody remember the Krogh principle?) while emphasizing that exosomes in this venue play a major role in what happens at fertilization [2]. This and related studies take us back to the inner depths of the reproductive tract on the male side as the problem of sperm maturation becomes more entwined with the deployment of membrane-bound vesicles harboring what appears to be an array of cargoes [3].

Among the cargoes are microRNAs capable of making epigenomic alterations in the sperm genome [4]. And even the "memory" basis for conversations held deep within the epididymal niche take advantage of well-honed and widely conserved signaling systems that will eventually influence sperm motility well down the line in both time and space [5]. The conundrum of how did we get from way back there to here in historical conversations between gametes and their niches is alive and well for many aspects of human ARTs.

Consider the accumulating evidence implicating exosomes as mediators of apoptosis [6] and implantation [7] while bearing in mind that much of what we do in the everyday practice of ARTs involves cleansing our gametes and embryos so thoroughly that any chance of these structures remaining in our baby-making cocktails is remote at best. This is not the first time exosomes have emerged on the pages of JARG, and a return trip is likely with the kind of research advances 
reminding us there is much more than genes dictating both reproductive fitness and the ways we try to manipulate reproductive processes [8].

\section{References}

1. Martin-DeLeon PA. Epididymosomes: transfer of fertilitymodulating proteins to the sperm surface. Asian J Androl. 2015;17(5):720-5.

2. Rowlison T, Ottinger MA, Comizzoli P. Key factors enhancing sperm fertilizing ability are transferred from the epididymis to the spermatozoa via epididymosomes in the domestic cat model. J Assist Reprod Genet. 2017. https://doi.org/10.1007/s10815-017-1083.

3. Sullivan R. Epididymosomes: role of extracellular microvesicles in sperm maturation. Front Biosci (Schol Ed). 2016;8:106-14.
4. Reilly JN, McLaughlin EA, Stanger SJ, Anderson AL, Hutcheon K, Church K, et al. Characterisation of mouse epididymosomes reveals a complex profile of microRNAs and a potential mechanism for modification of the sperm epigenome. Sci Rep. 2016;6:31794.

5. Murta D, Batista M, Silva E, Trindade A, Henrique D, Duarte A, et al. Notch signaling in the epididymal epithelium regulates sperm motility and is transferred at a distance within epididymosomes. Andrology. 2016;4(2):314-27.

6. Sun L, Li D, Song K, Wei J, Yao S, Li Z, et al. Exosomes derived from human umbilical cord mesenchymal stem cells protect against cisplatin-induced ovarian granulosa cell stress and apoptosis in vitro. Sci Rep. 2017;7(1):2552.

7. Salamonsen LA, Evans J, Nguyen HP, Edgell TA. The microenvironment of human implantation: determinant of reproductive success. Am J Reprod Immunol. 2016;75(3):218-25.

8. Albertini DF. Of exosomes and epididymsomes: how parental metabolism influences an embryos' fate. J Assist Reprod Genet. 2016;33(3):301-2. 